\title{
Aplikasi Biochar Sekam Padi dan Tepung Cangkang Kerang Untuk Meningkatkan Produktivitas Tanaman Kedelai Pada Tanah Sulfat Masam
}

\section{(Biochar Application of Rice Husk and Shellfish Flour To Increase Soybean Crop Productivity in Acid Sulphate Soil)}

\author{
Beny Setiawan ${ }^{1 *}$, Sutarman Gafur $^{1}$, dan Tatang Abdurrahman ${ }^{1}$ \\ ${ }^{1}$ Program Studi Magister Agroteknologi, Fakultas Pertanian, Universitas Tanjungpura Pontianak \\ Jl. Prof. Dr. H. Hadari Nawawi Pontianak 78124, Indonesia \\ *Email Korespondensi: benys780@gmail.com
}

Diterima 17 Juli 2019/Disetujui 03 September 2019

\begin{abstract}
The use of acid sulphate land for soybean cultivation has several problems such as low soil pH and available phosphate and high Fe content. The effort to overcome acid sulphate land margins is by adding biochar and calcification. The study was conducted using a Completely Randomized Design (CRD) consisting of two factors. The first factor is the dose of rice husk biochar with three levels of doses (0,5\% and 10\%) and the second factor is the dose of shellfish flour with three dosages (0, 12, $14 \mathrm{~g} /$ polybag and $24.28 \mathrm{~g} / \mathrm{polybag})$. The parameters observed were plant growth and yield. The results showed that application of shellfish flour with a dose of $24.28 \mathrm{~g} /$ polybag can increase the dry weight of the highest crop seeds, which is equal to 65.33 g/plant.
\end{abstract}

Keywords: biochar, shellfish, soybean, acid sulphate soil

\begin{abstract}
ABSTRAK
Penggunaan lahan sulfat masam untuk budidaya kedelai memiliki beberapa permasalahan seperti antara lain rendahnya pH tanah dan fosfat tersedia serta tingginya kandungan Fe. Upaya untuk mengatasi kemarginalan lahan sulfat masam adalah dengan penambahan biochar dan pengapuran. Penelitian dilaksanakan menggunakan Rancangan Acak Lengkap (RAL) yang terdiri dari dua faktor. Faktor pertama yaitu dosis biochar sekam padi dengan tiga taraf dosis (0, $5 \%$ dan $10 \%)$ dan faktor kedua yaitu dosis tepung cangkang kerang dengan tiga tara dosis (0, 12,14 g/polybag dan 24,28 g/polybag). Parameter yang diamati yaitu pertumbuhan dan hasil tanaman. Hasil penelitian menunjukkan bahwa aplikasi tepung cangkang kerang dengan dosis 24,28 g/polybag meningkatkan berat kering biji pertanaman tertinggi jika dibandingkan kontrol yaitu sebesar 65,33 g/tanaman.
\end{abstract}

Kata kunci: biochar,cangkang kerang,kedelai,tanah sulfat masam

\section{PENDAHULUAN}

Penggunaan lahan pasang surut untuk budidaya kedelai memiliki beberapa kendala yang harus dihadapi. Pengembagan pertanian di tanah sulfat masam sering menghadapai beberapa permasalahan seperti antara lain rendahnya $\mathrm{pH}$ tanah dan fosfat tersedia serta tingginya kandungan $\mathrm{Fe}$ (Purnomo et. al., 2005). Kedelai dapat berproduksi secara optimum pada keadaan $\mathrm{pH}$ tanah 6-6.8 dan akan terhambat pertumbuhannya ketika $\mathrm{pH} \leq 5.5$ karena keracunan aluminium. Hasil penelitian Uguru et. al. (2012) menunjukkan bahwa tingkat kemasaman tanah sangat berpengaruh terhadap pertumbuhan dan hasil kedelai.

Salah satu teknologi yang digunakan untuk mengatasi permasalahan pada tanah sulfat masam adalah teknologi biochar. Teknologi biochar dapat meningkatkan beberapa sifat kimia tanah seperti $\mathrm{pH}$, KTK, dan beberapa senyawa seperti C-organik, N-total, serta dapat mereduksi aktivitas senyawa $\mathrm{Fe}$ dan $\mathrm{Al}$ yang berdampak terhadap peningkatan $\mathrm{P}$ tersedia (Sudjana, 2014).

Selain dengan aplikasi biochar, untuk mengatasi kendala lahan rawa pasang surut adalah dengan aplikasi pembenah tanah seperti dolomit/kaptan (CaMg(CO3)2. Pengapuran meningkatkan $\mathrm{pH}$ tanah dan efisiensi pemupukan $\mathrm{P}$, bahkan mengekstrak $\mathrm{P}$ tanah yang terikat oleh $\mathrm{Al}$ atau $\mathrm{Fe}$. Pengapuran efektif dalam menghambat penurunan $\mathrm{pH}$ akibat oksidasi pirit pada tanah sulfat masam (Priatmadi dan Haris, 2009). Cangkang kerang M. meretrix diketahui memiliki kandungan kalsium yang tinggi yaitu $98.81 \%$ (Mijan et. al. 2015). Dengan kandungan kalsium yang tinggi Cangkang kerang memiliki potensi sebagai sumber garam mineral yang berperan penting dalam proses peningkatan $\mathrm{pH}$ tanah sulfat masam.

Adanya potensi sekam padi dan cangkang kerang yang dapat dimanfaatkan sebagai sumber bahan organik dan sumber mineral yang dapat digunakan untuk meningkatkan 
produktivitas tanah sulfat masam kiranya perlu dipelajari peranan arang sekam padi dan serbuk cangkang ale-ale

\section{BAHAN DAN METODE}

Penelitian ini dilaksanakan di Area Pertanian Percontohan Terpadu Desa Sungai Awan Kanan, Kecamatan Muara Pawan, Kabupaten Ketapang, Kalimantan Barat yang dilaksanakan selama 4 (empat) bulan yang dimulai dari bulan September 2018 sampai dengan bulan Januari 2019.

Alat yang digunakan dalam percobaan ini adalah : cangkul, sabit, parang, meteran, $\mathrm{pH}$ meter, termometer, neraca, sprayer alat tulis kantor dan alat pendukung lainnya. Bahan-bahan yang digunakan adalah Polybag ukuran $35 \mathrm{~cm}$ x $40 \mathrm{~cm}$, benih Kedelai varietas Devon 2, Arang Sekam Padi, Cangkang Kerang ale-ale, Bakteri Rhizobium, Regent, Pupuk NPK 15 dan Pestisida.

Penelitian dilaksanakan menggunakan Rancangan Acak Lengkap (RAL) faktorial yang terdiri dari dua faktor, faktor pertama adalah dosis arang sekam padi (S) dengan tiga taraf perlakuan yaitu $0,5 \%$ dan $10 \%$. Faktor kedua adalah dosis tepung cangkang kerang ale-ale dengan tiga taraf perlakuan yaitu $0,12,14 \mathrm{~g} /$ polybag dan 24,28 g/polybag. Banyaknya perlakuan dalam percobaan ini ada 9 kombinasi yaitu $\mathrm{S} 0 \mathrm{~K} 0, \mathrm{~S}_{0} \mathrm{~K}_{1}, \mathrm{~S}_{0} \mathrm{~K}_{2}, \mathrm{~S}_{1} \mathrm{~K}_{0}, \mathrm{~S}_{1} \mathrm{~K}_{1}, \mathrm{~S}_{1} \mathrm{~K}_{2}, \mathrm{~S}_{2} \mathrm{~K}_{0}, \mathrm{~S}_{2} \mathrm{~K}_{1}, \mathrm{~S}_{2} \mathrm{~K}_{2}$ dan diulang sebanyak $3 \mathrm{kali}$, setiap ulangan terdiri dari tiga tanaman sehingga jumlah seluruh tanaman sebanyak 81 tanaman.

Pengamatan dilakukan terhadap sifat kimia tanah $(\mathrm{pH}$ tanah, Ca, Mg, KTK, Aldd, Hdd dan N total) dan Pengamatan pertumbuhan tanaman, variabel pertumbuhan tanaman yang diamati yaitu Tinggi Tanaman, Jumlah cabang produktif, Jumlah Polong Bernas, Berat Biji Per Tanaman, Volume Akar, Berat Kering Akar dan Berat Kering Tajuk.

Untuk analisis data menggunakan analisis keragaman (ANOVA), bila terdapat perbedaan nyata diantara perlakuan atau kombinasinya diteruskan uji beda jarak nyata Duncan (DMRT) pada taraf $5 \%$.

\section{HASIL DAN PEMBAHASAN}

\section{Pengaruh Perlakuan Biochar sekam padi dan Tepung Cangkang Kerang Terhadap Pertumbuhan dan Hasil Tanaman}

\section{a. Tinggi Tanaman}

Analisis sidik ragam terhadap parameter pertumbuhan tanaman menunjukkan tidak ada interaksi untuk kombinasi perlakuan arang sekam dan tepung cangkang kerang kecuali untuk parameter berat kering tajuk terdapat interksi perlakuan arang sekam dengan tepung cangkang kerang.

Hasil uji lanjut terhadap parameter tinggi tanaman menunjukkan perlakuan biochar sekam padi secara tunggal tidak memberikan pengaruh terhadap peningkatan tinggi tanaman pada 4 MST dan 6 MST (Tabel 1). Hal ini ditunjukan pada perlakuan arang sekam dosis $5 \%\left(\mathrm{~S}_{1}\right)$ tidak bebeda nyata dengan perlakuan tanpa biochar sekam padi $\left(\mathrm{S}_{0}\right)$. terhadap pertumbuhan dan hasil tanaman kedelai di tanah sulfat masam.

Penambahan dosis biochar sekam padi menjadi $10 \%\left(\mathrm{~S}_{2}\right)$ tidak menunjukan peningkatan pada tinggi tanaman. Hal ini diduga karena perlakuan biochar sekam padi pada tanah dengan kandungan $\mathrm{C}$ organik tinggi tidak memberikan pengaruh signifikan terhadap peningkatan KTK tanah (Tabel 4) sehingga penambahan biochar sekam padi secara tunggal tidak berpengaruh terhadap peningkatan tinggi tanaman.

Perlakuan Tepung cangkang kerang menunjukkan pengaruh nyata terhadap tinggi tanaman. Untuk parameter tinggi tanaman perlakuan terbaik yaitu pada perlakuan tepung cangkang kerang dengan dosis 24,28 gram/polybag $\left(\mathrm{K}_{2}\right)$ dapat meningkatkan tinggi tanaman kedelai pada 6 MST tinggi tanaman mencapai $57,2 \mathrm{~cm}$ sedangkan pada perlakuan tanpa tepung cangkang kerang $\left(\mathrm{K}_{0}\right)$ tinggi tanaman hanya $45,8 \mathrm{~cm}$ (Tabel 1). Hal ini disebabkan karena penambahan tepung cangkang kerang ale ale dapat meningkatkan kandungan unsur $\mathrm{Ca}$ dan $\mathrm{Mg}$ di dalam tanah yang dibutuhkan pada proses pertumbuhan tanaman. Tepung cangkang kerang tepung cangkang kerang ale-ale mengandung 10,05\% Ca, $0,18 \% \mathrm{Mg}$ serta Daya netralisasi sebesar 98,83\%.

Penyediaan unsur $\mathrm{Ca}$ akan membantu pembentukan akar selain unsur $\mathrm{Ca}$, akar juga menyerap unsur $\mathrm{Mg}$ yang merupakan unsur penting dalam proses fotosintesis (Soverda dan Hermawati, 2009). Sesuai dengan pendapat Sumaryo dan Suryono (2000) yang mengatakan bahwa pengapuran dapat menambah ketersediaan $\mathrm{Ca}$ dan $\mathrm{Mg}$ dalam tanah, dengan demikian dapat memacu turgor sel dan pembentukan klorofil sehingga proses fotosintesis menjadi lebih meningkat. Fotosintat yang dihasilkan akan ditranslokasikan ke organ tanaman diantaranya batang untuk pertambahan tinggi tanaman.

\section{b. Jumlah Cabang Produktif}

Hasil analisis ragam parameter jumlah cabang produktif tanaman kedelai menunjukkan bahwa interaksi dari kombinasi dosis biochar sekam padi dengan dosis tepung cangkang kerang tidak berpengaruh nyata. Data pada Tabel 1 menunjukkan bahwa perlakuan dosis arang sekam tidak nyata mempengaruhi parameter jumlah cabang produktif tanaman kedelai. Namun penambahan tepung cangkang kerang dosis 24,28 $\mathrm{g} /$ polybag $\left(\mathrm{K}_{2}\right)$ dapat meningkatkan jumlah cabang produktif dibanding kontrol. Hal ini diduga karena tepung cangkang mengandung $\mathrm{Ca}$ yang dibutuhkan tanaman dalam jumlah besar untuk pertumbuhan vegetatif tanaman. Unsur $\mathrm{Ca}^{2+}$ berperan sebagai regulator pertumbuhan dan perkembangan tanaman. Sebagai kation divalent, unsur $\mathrm{Ca}^{2+}$, berperan dalam pembentukan dinding sel dan membran sel yang berperan dalam pemanjangan akar dan batang tanaman (White and Broadley, 2003). Perlakuan dengan jumlah cabang produkti terbanyak ditunjukan pada perlakuan tepung cangkang kerang dosis $24,28 \mathrm{~g} /$ polybag $\left(\mathrm{K}_{2}\right)$ yaitu sebesar 10,9 cabang sedangkan jumlah cabang produktif paling sedikit ditunjukan pada perlakuan tanpa tepung cangkang kerang $\left(\mathrm{K}_{0}\right)$ yaitu 9,5 cabang. 


\section{c. Volume Akar}

Tabel 3 menunjukkan perlakuan biochar sekam padi $\mathrm{S}_{1}$ berbeda nyata dengan perlakuan $\mathrm{S}_{0}$ namun tidak beda nyata terhadap perlakuan $S_{2}$. Perlakuan $S_{1}$ menunjukan nilai volume akar tertinggi yaitu $121,5 \mathrm{~cm}^{3}$, sementara volume akar terendah pada perlakuan $S_{0}$ yaitu $84,1 \mathrm{~cm}^{3}$. Perlakuan Tepung Cangkang $\mathrm{K}_{2}$ berbeda nyata dengan perlakuan tanpa tepung cangkang $\mathrm{K}_{0}$ tetapi tidak beda nyata dengan perlakuan $\mathrm{K}_{1}$ (Tabel 3). Nilai rerata volume akar tertinggi ada pada perlakuan tepung cangkang $\mathrm{K}_{2}$ yaitu sebesar $121,9 \mathrm{~cm}^{3}$ dan nilai terendah rerata volume akar ditunjukan pada perlakuan $\mathrm{S}_{0}$ yaitu sebesar $84,1 \mathrm{~cm}^{3}$.

Tabel 3. Pengaruh Arang sekam dan Tepung cangkang kerang Ale Ale terhadap Volume Akar.

Tabel 1. Pengaruh bochar sekam padi dan Tepung cangkang kerang teerhadap Tinggi Tanaman 4 MST dan 6 MST

\begin{tabular}{|c|c|c|}
\hline \multirow{2}{*}{ Perlakuan } & \multicolumn{2}{|c|}{ Tinggi Tanaman $(\mathrm{cm})$} \\
\hline & 4 MST & 6 MST \\
\hline Arang Sekam & & \\
\hline $\mathrm{S} 1(5 \%)$ & 27,277 a & $54,482 \mathrm{a}$ \\
\hline S0 (Tanpa arang sekam) & $25,611 \mathrm{ab}$ & $52,591 \mathrm{a}$ \\
\hline S2 $(10 \%)$ & $23,926 \mathrm{~b}$ & $48,298 \mathrm{~b}$ \\
\hline Tepung Cangkang & & \\
\hline K2 $(24,28 \mathrm{~g} /$ polybag $)$ & 28,166 a & $57,148 \mathrm{a}$ \\
\hline $\mathrm{K} 1(12,14 \mathrm{~g} /$ polybag $)$ & $25,686 \mathrm{~b}$ & $52,408 \mathrm{~b}$ \\
\hline K0 (Tanpa tepung cangkang) & $22,962 \mathrm{c}$ & $45,816 \mathrm{c}$ \\
\hline
\end{tabular}

Tabel 2. Pengaruh Arang sekam dan Tepung Cangkang Kerang terhadap Jumlah cabang produktif

\begin{tabular}{lc}
\multicolumn{1}{c}{ Perlakuan } & Jumlah Cabang Produktif (Cabang) \\
\hline Arang Sekam & $10,704 \mathrm{a}$ \\
S1 $(5 \%)$ & $10,517 \mathrm{a}$ \\
S2 $(10 \%)$ & $9,667 \mathrm{a}$ \\
S0 (Tanpa arang sekam) & \\
Tepung Cangkang & $10,926 \mathrm{a}$ \\
K2 (24,28 g/polybag) & $10,444 \mathrm{ab}$ \\
K1(12,14 g/polybag) & $9,518 \mathrm{~b}$ \\
K0 (Tanpa tepung cangkang) & \\
\hline
\end{tabular}

Keterangan: Angka yang diikuti huruf yang sama pada kolom yang sama tidak berbeda nyata berdasarkan uji DMRT 5\%

\begin{tabular}{lc}
\hline \multicolumn{1}{c}{ Perlakuan } & Volume Akar $\left(\mathbf{c m}^{3}\right)$ \\
\hline Arang sekam & $121,483 \mathrm{a}$ \\
S1(5\%) & $119,259 \mathrm{a}$ \\
S2 (10\%) & $84,073 \mathrm{~b}$ \\
S0 (Tanpa arang sekam) & \\
Tepung cangkang & $121,852 \mathrm{a}$ \\
K2 (24,28 g/polybag) & $110,370 \mathrm{ab}$ \\
K1(12,14 g/polybag) & $92,593 \mathrm{~b}$ \\
K0 (Tanpa tepung cangkang) & \\
\hline
\end{tabular}

Keterangan: Angka yang diikuti huruf yang sama pada kolom yang sama tidak berbeda nyata berdasarkan uji DMRT 5\% 
Tabel 4. Pengaruh Biochar sekam padi dan Tepung Cangkang Kerang Ale Ale terhadap Jumlah Polong Bernas

\begin{tabular}{lc}
\hline \multicolumn{1}{c}{ Perlakuan } & Jumlah Polong Bernas (polong) \\
\hline Arang Sekam & $141,333 \mathrm{a}$ \\
$\mathrm{S} 2(10 \%)$ & $112,333 \mathrm{~b}$ \\
$\mathrm{~S} 1(5 \%)$ & $96,482 \mathrm{~b}$ \\
$\mathrm{~S} 0$ (Tanpa arang sekam) & \\
Tepung cangkang & $157,667 \mathrm{a}$ \\
K2 (24,28 g/polybag) & $112,221 \mathrm{~b}$ \\
K1(12,14 g/polybag) & $80,261 \mathrm{c}$ \\
K0 (Tanpa tepung cangkang)
\end{tabular}

Keterangan: Angka yang diikuti huruf yang sama pada kolom yang sama tidak berbeda nyata berdasarkan uji DMRT 5\%

Tabel 5. Pengaruh Arang sekam dan Tepung Cangkang Kerang Ale Ale terhadap Berat Kering Biji

\section{Perlakuan}

Berat Kering Biji (gram)

$\begin{array}{ll}\text { Arang sekam } & 55,207 \mathrm{a} \\ \text { S2 }(10 \%) & 45,662 \mathrm{~b} \\ \text { S1 }(5 \%) & 36,916 \mathrm{c} \\ \text { S0 (Tanpa arang sekam) } & \\ \text { Tepung cangkang } & 65,329 \mathrm{a} \\ \text { K2 (24,28 g/polybag) } & 44,279 \mathrm{~b} \\ \text { K1(12,14 g/polybag) } & 28,177 \mathrm{c} \\ \text { K0 (Tanpa tepung cangkang) }\end{array}$

Keterangan: Angka yang diikuti huruf yang sama pada kolom yang sama tidak berbeda nyata berdasarkan uji DMRT 5\%

Tabel 6. Pengaruh Arang sekam dan Tepung cangkang kerang ale ale terhadap Berat Kering Akar

\begin{tabular}{lc}
\hline \multicolumn{1}{c}{ Perlakuan } & Berat Kering Akar (gram) \\
\hline Arang sekam & \\
S1 $(5 \%)$ & $25,449 \mathrm{a}$ \\
S2 $(10 \%)$ & $23,409 \mathrm{a}$ \\
S0 (Tanpa arang sekam) & $17,126 \mathrm{~b}$ \\
Tepung cangkang & $24,096 \mathrm{a}$ \\
K2 $(24,28 \mathrm{~g} /$ polybag) & $23,177 \mathrm{a}$ \\
K1(12,14 g/polybag) & $18,711 \mathrm{a}$ \\
K0 (Tanpa tepung cangkang) & \\
\hline
\end{tabular}

Keterangan: Angka yang diikuti huruf yang sama pada kolom yang sama tidak berbeda nyata berdasarkan uji DMRT $5 \%$

Tabel 7. Pengaruh Arang sekam dan Tepung cangkang kerang ale ale terhadap Berat Kering Tajuk

\begin{tabular}{cccc}
\hline Perlakuan & $\mathbf{S}_{\mathbf{0}}$ & $\mathbf{S}_{\mathbf{1}}$ & $\mathbf{S}_{\mathbf{2}}$ \\
\hline $\mathrm{K}_{0}$ & $10,1 \mathrm{e}$ & $21,6 \mathrm{abcd}$ & $16,1 \mathrm{ced}$ \\
$\mathrm{K}_{1}$ & $30,5 \mathrm{ab}$ & $27,4 \mathrm{abc}$ & $13,5 \mathrm{de}$ \\
$\mathrm{K}_{2}$ & $27,1 \mathrm{abc}$ & $32,9 \mathrm{a}$ & $19,1 \mathrm{bcde}$ \\
\hline
\end{tabular}

Keterangan: Angka yang diikuti huruf yang sama pada kolom yang sama tidak berbeda nyata berdasarkan uji DMRT 5\%

Pertumbuhan akar pada kondisi tanpa tepung cangkang kerang menjadi terhambat, hal ini dapat dilihat pada volume akar dengan perlakuan perlakuan tanpa tepung cangkang kerang $\left(\mathrm{K}_{0}\right)$ hanya $92,59 \mathrm{~cm}^{3}$ (Tabel 3). Hal ini disebabkan tanaman kedelai mengalami keracunan logam yang terlarut pada kondisi kemasaman tanah yang tinggi. Menurut Uguru et. al. (2012), kemasaman tanah yang tinggi menyebabkan tingginya kelarutan $\mathrm{Al}^{3+}$ yang bersifat toksik 
bagi tanaman. Aluminium berpengaruh terhadap proses pembelahan dan pemanjangan sel meristematik di akar, sehingga menghambat pertumbuhan akar dan mengurangi penyerapan air dan hara terutama $\mathrm{Ca}, \mathrm{Mg}$ dan $\mathrm{P}$ yang berperan dalam proses fisiologi dan biokimia tanaman.

Pemberian tepung cangkang kerang dengan dosis $24,28 \mathrm{~g} /$ polybag dapat meningkatkan $\mathrm{pH}$ tanah dan menurunkan kelarutan $\mathrm{Al}^{3+}$, sehingga dapat meningkatkan pertambahan volume akar tanaman kedelai sebesar 121,85 $\mathrm{cm}^{3}$ (Tabel 3). Hal ini sesuai dengan pernyataan Hakim dkk (1986), pengaruh tidak langsung dari pengapuran ialah perbaikan ciri-ciri kimia tanah seperti: $\mathrm{pH}, \mathrm{Ca}$, dan unsur hara lainya yang meningkat. Al-dd dan kejenuhan Al yang berkurang, akibat penambahan kapur dolomit menciptakan suasana tumbuh yang baik bagi akar.

Pengaruh yang sama ditunjukan pada perlakuan biochar sekam padi dosis $10 \%$ dapat meningkatkan $\mathrm{pH}$ tanah. Nilai $\mathrm{pH}$ di atas 5,5 $\mathrm{Al}$ akan mengendap sebagai $\mathrm{Al}(\mathrm{OH})_{3}$, sehingga akan menurunkan sifat racun $\mathrm{Al}^{3+}$. Selain memperbaiki sifat kimia tanah, penambahan biochar sekam padi juga memperbaiki sifat fisik tanah menjadi lebih porus sehingga memberi lingkungan yang baik bagi perkembagan akar. Menurut Santi dan Goenadi (2010) ruang pori total meningkat akibat berat isi tanah menurun sebagai akibat penambahan biochar sekam padi ke dalam tanah.

\section{d. Jumlah Polong Bernas}

Hasil uji lanjut menunjukkan perlakuan biochar sekam padi $\mathrm{S}_{2}$ berbeda nyata dengan perlakuan $\mathrm{S}_{0}$. Sementara perlakuan $S_{1}$ tidak berbeda nyata dengan perlakuan $S_{0}$. Perlakuan biochar sekam $\mathrm{S}_{2}$ memberikan hasil jumlah polong bernas paling banyak yaitu 141,3 polong dan jumlah polong paling sedikit pada perlakuan $S_{0}$ yaitu 96,5 polong (Tabel 4). Perlakuan biochar sekam padi diketahui dapat meningkatkan jumlah $\mathrm{P}$ tersedia dalam tanah. Terpenuhinya kebutuhan hara $\mathrm{P}$ maka akan meningkatkan aktivitas metabolisme sehingga bahan organik yang ditranslokasikan ke biji atau polong kacang tanah juga meningkat. Menurut Hardjoloekito (2009), unsur fosfor sangat diperlukan untuk pembentukan atau pertumbuhan generatif tanaman. Adanya unsur fosfat yang cukup dalam tanah dapat memacu pembentukan polong pada tanaman. Sementara perlakuan tepung cangkang kerang dapat meningkatkan jumlah unsur $\mathrm{Ca}$ dan $\mathrm{Mg}$ dalam tanah, unsur $\mathrm{Mg}$ sangat diperlukan untuk pembentukan klorofil yang mempengaruhi proses fotosintesis, semakin baik proses fotosintesis pada tanaman maka semakin tinggi pula fotosintat yang disimpan pada biji. Nurjayanti (2012) juga menambahkan bahwa unsur $\mathrm{Ca}$ merupakan hara yang paling menentukan tingkat kebernasan polong. Perlakuan tepung cangkang kerang 24,28 g/polybag $\left(\mathrm{K}_{2}\right)$ memberikan hasil jumlah polong paling tinggi dibanding perlakuan dosis tepung cangkang yang lain yaitu sebesar 157,67 polong.

\section{e. Berat Kering Biji Per Tanama}

Hasil uji lanjut pada parameter berat kering biji pertanaman (Tabel 5) menunjukan perlakuan biochar sekam padi dapat meningkatkan berat kering biji pertanaman dibandingkan dengan perlakuan tanpa biochar sekam padi. Perlakuan terbaik pada dosis biochar sekam padi $10 \%\left(\mathrm{~S}_{2}\right)$ meningkatkan berat kering biji pertanaman menjadi 55,21 gram sedangkan perlakuan tanpa biochar sekam padi $\left(\mathrm{S}_{0}\right)$ hanya memberikan berat kering biji pertanaman sebesar 36,92 gram. Hal ini diduga karena pengaruh dari penambahan biochar sekam padi ke dalam media tanah menyebabkan meningkatnya ketersediaan unsur $\mathrm{P}$ dalam tanah. Sesuai dengan pendapat Hidayat (2008), bertambahnya suplai fosfor dalam tubuh tanaman akan meningkatkan metabolisme sehingga proses pengisian biji optimal dan berat biji meningkat.

Perlakuan tepung cangkang kerang dosis 24,48 $\mathrm{g} /$ polybag menghasilkan berat biji paling tinggi diantara semua taraf perlakuan yaitu sebesar $65.33 \mathrm{~g} / \mathrm{tanaman}$. sedangkan pada perlakuan tanpa tepung cangkang kerang hanya sebesar $28.18 \mathrm{~g} /$ tanaman. Hal ini disebabkan karena penambahan tepung cangkang kerang dapat meningkatkan jumlah unsur $\mathrm{Ca}$ dan $\mathrm{Mg}$ dalam tanah. Unsur $\mathrm{Ca}$ dan $\mathrm{Mg}$ sangat diperlukan untuk pembentukan klorofil yang mempengaruhi proses fotosintesis, semakin baik proses fotosintesis pada tanaman maka semakin tinggi pula fotosintat yang disimpan pada biji, sehingga menambah berat biji tanaman kedelai (Sumaryo dan Suryono, 2000).

\section{f. Berat Kering Akar}

Hasil analisis sidik ragam menunjukan bahwa perlakuan arang sekam memberikan pengaruh nyata terhadap berat kering akar. Sementara perlakuan tepung cangkang tidak memberikan pengaruh nyata terhadap peningkatan berat kering akar. Interaksi pada perlakuan biochar sekam padi dengan tepung cangkang kerang pada parameter berat kering akar

Data Tabel 6 menunjukkan bahwa perlakuan biochar sekam padi memberikan pengaruh nyata pada peningkatan berat kering akar. Berat kering akar tertinggi pada perlakuan dosis $5 \%$ sebesar 25,45 gram tidak berbeda nyata dengan dosis $10 \%$ namun lebih tinggi dari perlakuan tanpa biochar sekam padi yaitu hanya sebesar 17,13 gram. Hal ini diduga dengan penambahan biochar sekam padi dapat memperbaiki sifat kimia tanah yaitu meningkatkan ketersediaan unsur $\mathrm{P}$ dalam tanah yang mempengaruhi proses perkembangan sel meristem akar. Hal ini sesuai dengan Hardjoloekito (2009) yang menyatakan bahwa fosfor merupakan bagian dari inti sel dan sangat penting dalam pembelahan sel, perkembangan jaringan meristem.

Selain memperbaiki sifat kimia tanah penambahan biochar sekam padi juga dapat memperbaiki sifat fisik tanah menjadi lebih porus sehingga memberikan lingkungan yang baik untuk perkembangan akar. Hal ini sesuai dengan Gani (2009) yang menyatakan bahwa penambahan biochar ke dalam tanah meningkatkan ketersediaan kation utama dan $\mathrm{P}$, biochar dapat berperan sebagai pembenah tanah yang memicu pertumbuhan tanaman dengan mensuplai dan menahan hara disamping peran lainnya yang dapat memperbaiki sifat fisik dan biologi tanah. Sementara perlakuan tepung cangkang kerang memberikan pengaruh terhadap penurunan $\mathrm{Al}_{\mathrm{dd}}$ dalam tanah yang bersifat racun bagi tanaman, sehingga proses 
pembelahan sel meristem dan pertumbuhan akar tanaman tidak terganggu.

\section{g. Berat Kering Tajuk}

Analisis sidik ragam terhadap parameter berat kering tajuk menunjukkan ada pengaruh interaksi perlakuan biochar sekam padi dengan tepung cangkang kerang. Data uji lanjut untuk parameter berat kering tajuk (Tabel 7) menunjukan perlakuan biochar sekam padi $5 \%$ dan tepung cangkang kerang 24,48 $\mathrm{g} /$ polybag $\left(\mathrm{S}_{1} \mathrm{~K}_{2}\right)$ dapat meningkatkan berat kering tajuk sebesar 26,34 gram lebih besar dibanding dengan perlakuan tanpa biochar sekam padi dan tepung cangkang kerang $\left(\mathrm{S}_{0} \mathrm{~K}_{0}\right)$ yang hanya 15,95 gram, hal ini diduga disebabkan karena tepung cangkang kerang mengandung $\mathrm{Ca}$ yang dibutuhkan tanaman dalam jumlah besar untuk pertumbuhan vegetatif tanaman. Unsur $\mathrm{Ca}^{2+}$ berperan sebagai regulator pertumbuhan dan perkembangan tanaman. Sebagai kation divalent, unsur $\mathrm{Ca}^{2+}$, berperan dalam pembentukan dinding sel dan membran sel yang berperan dalam pemanjangan akar dan batang tanaman (White and Broadley, 2003). Sementara dengan penambahan arang sekam dapat memperbaiki sifat fisik dan kimia tanah sehingga dapat meningkatkan ketersediaan unsur hara dalam tanah yang dibutuhkan untuk pertumbuhan tajuk tanaman. Menurut Sujana (2014) manfaat biochar antara lain dapat meretensi hara, mensuplai hara menurunkan meningkatkan $\mathrm{pH}$ sesuai kondisi pH tanah, meningkatkan KTK, meningkatkan ketersediaan hara.

\section{KESIMPULAN}

1. Aplikasi biochar sekam padi maupun tepung cangkang kerang ale ale berpengaruh nyata terhadap pertumbuhan dan hasil tanaman kedelai di tanah sulfat masam.

2. Interaksi kombinasi perlakuan biochar sekam padi dengan tepung cangkang kerang berpengaruh tidak nyata terhadap parameter tinggi tanaman, jumlah cabang produktif, jumlah polong bernas, volume akar, berat kering biji pertanaman dan berat kering akar. Namun berpengaruh nyata terhadap parameter berat kering tajuk.

3. Hasil terbaik perlakuan biochar sekam padi ditunjukan pada dosis $10 \%$, sedangkan untuk perlakuan tepung cangkang kerang ale ale hasil terbaik ditunjukan pada perlakuan dosis $24,28 \mathrm{~g} /$ polybag.

\section{DAFTAR PUSTAKA}

Agusni., dan Satriawan, H. 2012. Perubahan kualitas tanah ultisol akibat penambahan berbagai sumber bahan organik. Universitas Almuslim Bireuen. Jurnal Ilmiah Sains dan Teknologi. 12(3):32-36.

Alihamsyah, T. 2001. Prospek pengembangan dan pemanfaatan lahan pasang surut dalam perspektif eksplorasi sumber pertumbuhan pertanian masa depan. Hal:1-18. Dalam: Ar-Riza, I., T.Alihamsyah, M. Sarwani (eds). Pengelolaan Tanah dan Air di Lahan
Pasang Surut. Monograf Balai Penelitian Tanaman Pangan Lahan Rawa Banjarbaru.

Akande, M.O., E.A. Makinde, F.I. Oluwatoyinbo dan M.T. Adetunji. 2010. Effect of phosphate rock application on dry matter yield and phosphorus recovery of maize and cowpea grown in sequence. African Journal of Environmental Science and Technologi. 4(5):293-30

Cheng, C.H., J. Lehmann, J.E. Thies, S.D. Burton dan M.H. Engelhard. 2006. Oxidation of black carbon through biotic and abiotic processes. Organic Geochemistry, 37:1477-1488.

Hakim, N., M.Y. Nyakpa, A.M. Lubis, S.G. Nugroho, M.R. Saul, M.A. Diha, G.B. Hong dan H.H. Bayley, 1986. Dasar-Dasar Ilmu Tanah. Lampung (ID): Universitas Lampung.

Hardjoloekito, A.J.H. 2009. Pengaruh pengapuran dan pemupukan $\mathrm{P}$ terhadap pertumbuhan dan hasil tanaman kedelai (Glycine max L.) pada tanah latosol. Jurnal Media Soerjo, 5(2):1-19.

Hidayat N. 2008. Pertumbuhan dan produksi kacang tanah (Arachis hypogaea (L.)) varietas lokal madura pada berbagai jarak tanam dan dosis pupuk fosfor.Fakultas Pertanian Universitas Trunojoyo. Agrovigor, 1(1):5564.

Mijan, N.A., Y.H. Yap dan H.V. Lee. 2015. Synthesis of clamshell derived $\mathrm{Ca}(\mathrm{OH})_{2}$ nano-particles via simple surfactant-hydration treatment. Chemical Engineering. 262:1043-1051. doi:10.1016/j.cej.2014.10.069.

Priatmadi, B.J. dan A. Haris. 2009. Reaksi pemasaman senyawapirit pada tanah rawa pasang surut. J. Tanah Tropika 14(1):19-24.

Purba, M.A., F. Fauzi, dan K. Sari. 2015. Pengaruh Pemberian Fosfat Alam dan Bahan Organik pada Tanah Sulfat Masam Potensial Terhadap P-Tersedia Tanah dan Produksi Padi (Oryza sativa L.). Agroekoteknologi, 3(3).

Purnomo, E., A. Mursyid, M. Syarwani, A. Jumberi, Y. Hashidoko, T. Hasegawa, S. Honma, dan M. Osaki. 2005. Phosphorus solubilizing microorganisms in the rhizosphere of local rice verities grown without fertilizer on acid sulphate soils. Soil Sci. Plant Nutr., 51(5):679-681.

Pusat Penelitian Tanah. 1983. Jenis dan macam tanah di indonesia untuk keperluan survey dan pemetaan tanah daerah transmigrasi. Pusat Penelitian Tanah. Bogor.

Santi, L.P., dan Goenadi, D.H. 2010. Pemanfaatan biochar sebagai pembawa mikroba untuk pemantap agregat 
tanah Ultisol dari Taman Bogo-Lampung. Menara Perkebunan, 78(2):52-60.

Suastika, I.W., W. Hartatik dan I.G.M. Subiksa. 2006. Karakteristik dan teknologi pengelolaan lahan sulfat masam mendukung pertanian ramah lingkungan. Balitbangtan.

Sudjana, B. 2014. Pengaruh biochar dan NPK majemuk terhadap biomas dan serapan nitrogen di daun tanaman jagung (Zea mays) pada tanah typic dystrudepts. Ilmu Pertanan dan Perikanan. 3(1):63-66.

Soepardi G. 1983. Sifat dan Ciri Tanah. Bogor (ID): IPB press.

Soverda, N dan T. Hermawati. 2009. Respon tanaman kedelai (Glycine max (L.) Merill) terhadap pemberian berbagai konsentrasi pupuk hayati. Jurnal Agronomi. 13(1).

Sumaryo dan Suryono. 2000. Pengaruh pupuk dolomitdan SP-36 terhadap jumlah bintil akar dan hasil tanaman kacang tanah di tanah latosol. Jurnal Agrosains, 2(2):54- 58

Uguru, M.I., B. Oyiga dan E.A. Jandong. 2012. Responses of some soybean genotypes to different soil $\mathrm{pH}$ regimes in two planting seasons. The African Journal of Plant Science and Biotechnology 6(1):26-37.

White, P. dan M.R. Broadley. 2003. Calcium in Plants. Annual Botani-London 92, 487-511. 